
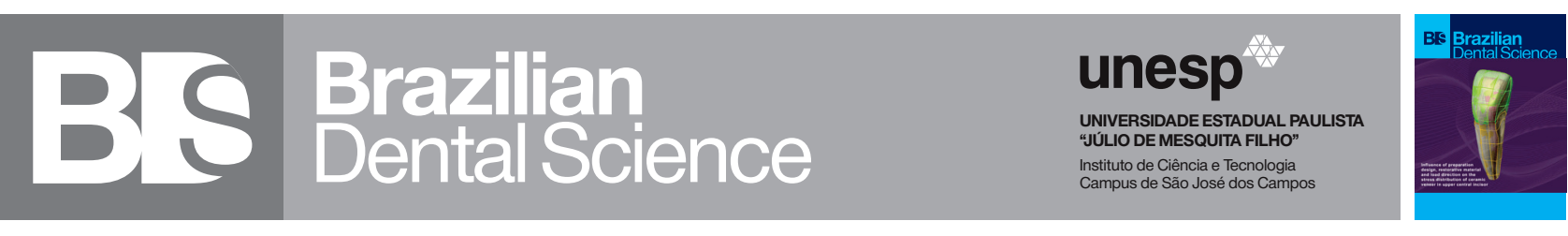

\title{
The Effect of Different Surface Treatment Protocols on the Shear Bond Strength to Repressed Lithium Disilicate Glass Ceramics
}

Efeito de diferentes protocolos de tratamento de superfície na resistência ao cisalhamento de vitrocerâmica de dissilicato de lítio reprensado

Amr EL-ETREBY ${ }^{1}$, Osama ALSHANTI ${ }^{2}$, Gehan EL NAGAR ${ }^{2}$

1 - Faculty of Dentistry, Ain Shams University, Cairo, Egypt.

2 - Faculty of Oral and Dental Medicine, Cairo University, Cairo, Egypt.

\section{ABSTRACT}

Objective: The present study aimed to evaluate the effect of repressing and different surface treatment protocols on the shear bond strength of lithium disilicate glass-ceramics. Material and Methods: A total of 52 lithium disilicate glass-ceramic discs (IPS emax Press, Ivoclar Vivadent) were fabricated using the heat-press technique. The discs were divided into two groups; group (P): discs fabricated from new e.max ingots $(n=26)$, group $(R)$ : discs fabricated from reused e.max buttons $(\mathrm{n}=26)$. Each group was subdivided into subgroup (E): discs were etched with hydrofluoric acid $(9.5 \%)(n=13)$, subgroup $(S)$ : discs were air-abraded with $110 \mu \mathrm{m}$ alumina particles. All specimens were subjected toX-ray Diffraction analysis, Scanning Electron Microscope, Energy Dispersive X-Ray, Thermo-Cycling, and Shear Bond Strength Testing. Results: Repressed Etched subgroup (RE) recorded the statistically highest shear bond strength value, followed by the Pressed Etched subgroup (PE), while the statistically lowest shear bond strength value was recorded for the Pressed Air-Abraded subgroup (PS) and Repressed Air-Abraded subgroup (RS). Conclusion: Repressing the leftover buttons for the construction of new lithium disilicate glass-ceramic restorations has no adverse effect on the bond strength of the resin cement to the ceramic. Hydrofluoric acid surface treatment improves the shear bond strength and durability of resin cement bond to both pressed and repressed lithium disilicate glassceramic. Air-abrasion cannot be considered as a reliable surface treatment when bonding to lithium disilicate glass-ceramics.

\section{KEYWORDS}

Heat pressed; Lithium disilicate glass-ceramics; Repressing; Shear bond strength; Surface treatment.

\section{RESUMO}

Objetivo: O presente estudo teve como objetivo avaliar o efeito da reprensagem e de diferentes protocolos de tratamento de superfície na resistência ao cisalhamento de vitrocerâmica de dissilicato de lítio. Materiais e Métodos: Um total de 52 discos de vitrocerâmica de dissilicato de lítio (IPS emax Press, Ivoclar Vivadent) foram fabricadas usando a técnica de prensagem quente. Os discos foram divididos em dois grupos: grupo $(\mathrm{P})$ : discos fabricados a partir de novo lingotes de e-max $(n=26)$, grupo $(R)$ : discos fabricados a partir de botões de emax reutilizados $(n=26)$. Cada grupo foi subdividido em subgrupo (E): discos condicionados com ácido fluorídrico $(9,5 \%)(\mathrm{n}=13)$, subgrupo $(\mathrm{S})$ discos foram abrasivos com partícula $110 \mu \mathrm{m}$ de alumínio. Todos os espécimes foram submetidos a analise de difração de raio-x, microscópio eletrônico de varredura, raio-x de energia dispersiva, termociclagem e teste de resistência de cisalhamento. Resultados: O subgrupo Reprensadocondicionado (RE) registrou o valor estatisticamente mais alta em relação a resistência ao cisalhamento, seguido pelo subgrupo Prensado-condicionado (PE), enquanto o valor estatisticamente mais baixo de resistência ao cisalhamento foi o subgrupo Prensado-Jateado (OS) e o subgrupo Reprensado-Jateado (RS). Conclusão: A reprensagem dos botões restantes para a construção de novas restaurações vitrocarâmicas de dissilicato de lítio não apresentou efeitos adversos na resistência de unicãp do cimento resinoso à cerâmica. O tratamento de superfície com ácido fluorídrico melhora a resistência ao cisalhamento e a durabilidade do cimento resinoso para vitrocerâmica de dissilicato de lítio prensada e reprimida. A abrasão por ar não pode ser considerada um tratamento de superfície confiável quanto a colagem da vitrocerâmica de dissilicato de lítio.

\section{PALAVRAS-CHAVE}

Prensagem quente; Vitrocerâmica de dissilicato de lítio; Reprensagem; Resistência ao cisalhamento; Tratamento de superfície. 


\section{INTRODUCTION}

$\mathrm{D}$ ental practitioners have adopted glassceramic restorations due to their ability to mimic natural tooth structure esthetics. Lithium disilicate glass-ceramics contains a $70 \%$ crystalline phase that increases its flexural strength than that of leucite reinforced glassceramics. [1,2] Lithium disilicate glass-ceramics have superior clinical properties; they bond adhesively to dental tissues, have high esthetics and biocompatible. These optimum optical and mechanical properties lead to high survival rates and hence their wide use in dentistry to restore lost and decayed teeth [3-11].

Lithium disilicate glass-ceramic restorations are cemented traditionally with glass ionomer cements or bonded adhesively with resin cements. [12,13] Adhesive bonding is recommended as its strength is superior to traditional cementation, [14-16] and also it increases the fracture resistance of lithium disilicate restorations. [17] Hydrofluoric acid (HF) etching has been recommended before the resin cement application, [18] as it partially dissolute the glassy phase $[14,15]$ exposing the crystalline phase and increasing the surface area for bonding, [16-18] thus improving the bond strength of resin cement to lithium disilicate glass-ceramics. [19-23] The application of silane coupling agent will follow this, then a thin layer of unfilled resin is applied to promote a better infiltration to the surface irregularities of the etched lithium disilicate ceramic surfaces. [24,25]

Several studies compared etching with hydrofluoric acid to other surface treatments as air-abrasion and reported a decrease in shear bond strength when the heat-pressed glassceramic surface was air-abraded with alumina oxide particles. [26-30]

Heat-pressing of lithium disilicate glassceramics utilizes the lost wax technique. It has been reported that some dental laboratories reuse the residual glass-ceramic materials remaining from the heat-pressing procedures to press new restorations. [31,32] Studies showed that repressing did not affect biaxial flexural strength (BFS), [31,32]. Hardness and flexural toughness [32] of heat-pressed glass-ceramics. In contrast to an another study, which reported a significant increase in BFS of repressed glassceramic material. [33] X-ray diffraction (XRD) and scanning electron microscopy (SEM) showed no difference in the crystalline composition of repressed glass-ceramics. Finally, it was concluded that lithium disilicate glass-ceramic could be repressed while maintaining good mechanical properties and without significantly altering the crystalline composition. [31-33]

The recycling of heat pressed lithium disilicate glass-ceramic leftover material has been reported to be done by dental laboratories. The effect of this procedure on the shear bond strength of repressed lithium disilicate glassceramic material is unknown, and has not yet been investigated especially with subsequent exposure to temperature changes. The present study aimed to evaluate the effect of repressing and different surface treatment protocols on the shear bond strength of lithium disilicate glass-ceramics. The null hypothesis is that the processing technique, as well as different surface treatment protocols, will have no significant effect on the shear bond strength of lithium disilicate glass-ceramics.

\section{MATERIAL AND METHODS}

A total of 52 lithium disilicate glass-ceramic discs (IPS emax Press, Ivoclar Vivadent) were fabricated by using the heat-press technique. The discs were divided into two groups; group (P): discs fabricated from new e.max ingots $(n=26)$, group (R): discs fabricated from reused e.max buttons $(n=26)$. Each group was subdivided into subgroup $(E)$ : discs were etched with hydrofluoric acid (9.5\%) $(n=13)$, subgroup (S): discs were air-abraded with 110 um alumina particles. To fabricate specimens of group (P), wax discs (Geo Classic, Renfert) of $10 \mathrm{~mm}$ diameter and $2 \mathrm{~mm}$ thickness, were fabricated with the aid of a specially designed Teflon mold. The discs were sprued and invested (IPS 
PressVest Premium, Ivoclar Vivadent) according to the manufacturer instructions. After the investment set (30 minutes), the investment ring was placed inside a burnout furnace (Ney, US Dental) for wax elimination according to manufacturer instructions. The ring was then transferred to a porcelain furnace (EP 3000, Ivoclar Vivadent), where it was heat-pressed using lithium disilicate glass-ceramic (A3, LT, IPS emax Press, Ivoclar Vivadent). After cooling (1 hour), rough divesting was done under 4 bar pressure followed by soft divesting under 2 bar pressure using $110 \mu \mathrm{m}$ alumina particles. The pressed object was placed in a $1 \%$ hydrofluoric acid (Invex liquid, Ivoclar Vivadent) for 10 minutes, then washed with water, air-dried, and air-abraded with $110 \mu \mathrm{m}$ alumina particles under 2 bar pressure to remove the remaining reaction layer. The discs were then cut from the sprues, and the remaining button was finished to resemble a new ingot using diamond stones. The leftover buttons were heat-pressed to fabricate the discs of group (R).

\section{X-ray Diffraction (XRD)}

$\mathrm{X}$-ray Diffraction analysis was carried out to study the produced phases by using the PANanalytical X-Ray Diffraction equipment model X'Pert PRO with Secondary Monochromator, Cu-radiation $(\lambda=1.542 \AA)$ at 45 K.V., 35 M.A. and scanning speed $0.04 \mathrm{o} /$ seconds. The diffraction peaks between $2 \theta$ $=2 \mathrm{o}$ and $60 \mathrm{o}$, corresponding spacing $(\mathrm{d}, \AA)$ and relative intensities (I/Io) were obtained and compared with ICDD files.

\section{Scanning Electron Microscope (SEM) and Energy Dispersive X-ray (EDX)}

The SEM was carried out (at 6000x and 10000x) to study the surface topography of specimens using SEM Model Quanta 250 FEG (Field Emission Gun) attached with EDX Unit to study the elemental structure of specimens, with accelerating voltage $30 \mathrm{~K} . \mathrm{V}$., magnification $14 \mathrm{x}$ up to 1000000 and resolution for Gun.1n.

\section{Surface Etching protocol}

Group (E) specimens were etched for 20 seconds with $9.5 \%$ buffered hydrofluoric acid
(Porcelain Etchant, Bisco), then rinsed with water, dried with oil-free moisture-free air, followed by silane coupling agent application (Porcelain Primer, Bisco) for 60 seconds then air-dried for 5 seconds. [3,22,23]

\section{Air-Abrasion protocol}

Group (S) specimens were air-abraded with $110 \mu \mathrm{m}$ aluminum oxide particles (Renfert) under pressure $2.8 \mathrm{~atm}$, from a $1 \mathrm{~mm}$ distance for 15 seconds, then cleaned with alcohol, dried with oil-free moisture-free air, followed by silane coupling agent (Porcelain Primer, Bisco) application for 60 seconds then air-dried for 5 seconds. [26-30]

To ensure a standardized resin cement dimensions and to allow the mono-beveled chisel of the universal testing machine to introduce a compressive force at the ceramic resin interface, a pediatric catheter was cut into a height of $2 \mathrm{~mm}$ piece and attached using a single bond universal to the center of each disc. Care was taken not to contaminate the center of the disc with the adhesive bond. The catheter was secured in place by using light-cure for 20 seconds from all aspects, then the catheter was filled with dual-cure self-adhesive resin cement (Breeze, Pentron) and cured for 20 seconds from all aspects. After curing, the catheter was cut using a sharp lancet leaving a $2 \mathrm{~mm}$ height cylinder of resin cement attached to the disc and ready to be tested. $[34,35]$

\section{Thermo-Cycling}

Thermal aging was performed for all specimens after adhesive bonding using Robota automated thermal cycle (BILGE, Turkey). The number of cycles was 5000 cycles (equivalent to 6 months inside oral condition). Dwell times were 25 in each water bath with a lag time of 10 seconds. The low-temperature point was $5{ }^{\circ} \mathrm{C}$. The high-temperature point was $55^{\circ} \mathrm{C}$. [36,37]

\section{Shear Bond Strength Testing}

A circular interface shear test was performed using a computer-controlled materials testing machine (Model 3345) with a loadcell of $5 \mathrm{KN}$. The data were recorded 
using computer software (Bluehill Lite; Instron Instruments). Each disc was fixed to a specially designed specimen holder [metal tube with a central hole for ceramic disc housing] secured to the lower fixed compartment of the testing machine by tightening screws. The shear test was done at the ceramic-resin interface using a mono-beveled chisel-shaped metallic rod attached to the upper movable compartment of the testing machine traveling at a cross-head speed of $0.5 \mathrm{~mm} / \mathrm{minute}$. The load required for debonding was recorded in Newton. The load at failure was divided by bonding area to express the bond strength in MPa through the following equation; $[\mathrm{T}=\mathrm{p} / \pi \mathrm{r} 2$ ] where; $\mathrm{T}=$ shear bond strength (MPa), $\mathrm{p}=$ load at failure $(\mathrm{N}), \pi=3.14$ and $\mathrm{r}=$ radius of resin disc $(\mathrm{mm})$.

\section{Mode of Failure}

To determine the nature of failure modes, all specimens were examined by using a USB digital microscope at $25 \mathrm{x}$ magnification and photographed using image analysis software (Scope Capture 1.1.1.1. Ltd Co.). Failure type was noted as adhesive, cohesive, or mixed.

Data were collected and presented as mean, standard deviation (SD). The results were analyzed with Graph Pad Instat (Graph Pad, Inc.) software for windows. A value of $P$ $<0.05$ was considered statistically significant. After homogeneity of variance and normal distribution of errors had been confirmed, a two-way analysis of variance was performed to detect the effect of each variable. Student t-test was done for compared pairs. Chi-square test was done between different failure modes. The sample size $(n=13)$ was large enough to detect large effect sizes for main effects and pair-wise comparisons, with the satisfactory level of power set at $80 \%$ and a $95 \%$ confidence level.

\section{RESULTS}

X-ray diffraction analysis: The X-ray analysis of both pressed and repressed specimens showed that the material is predominantly crystalline structure; lithium disilicate was identified to be the main crystalline phase
(Figure 1).

Energy Dispersive x-ray analysis: EDAX results showed no change in composition between pressed and repressed specimens (Figure 2).

\section{Scanning Electron Microscope (SEM)}

For the (E) group: after surface treatment with hydrofluoric acid, it is possible to observe a deeper etching pattern with glassy dissolution and exposition of crystals in the (PE) specimens, while the (RE) specimens showed a more homogenized surface with the persistence of crystals. Regarding the (S) group: the surface of the (PS) specimens is characterized by various deep grooves, valleys and irregularly shaped defects, while that of the (RS) specimens showed crater-shaped cavities that are larger in size and greater in number than that of PS specimens indicating more surface micro-roughness (Figure 3 and 4).

\section{Shear bond strength}

The results of this study showed that; the (RE) subgroup recorded the statistically highest shear bond strength value (9.5 $\mathrm{MPa}$ ) followed by (PE) subgroup (7.95 $\mathrm{MPa}$ ) at $\mathrm{p}<0.05$, while the statistically lowest shear bond strength value was recorded for the (PS) subgroup (4.00 $\pm 0.79 \mathrm{MPa})$ and $(\mathrm{RS})$ subgroup (3.9 $\mathrm{MPa})$ at $\mathrm{p}<0.05$ (Table I, Figure 5).

Table I - Shear bond strength for both groups as a function of surface treatment

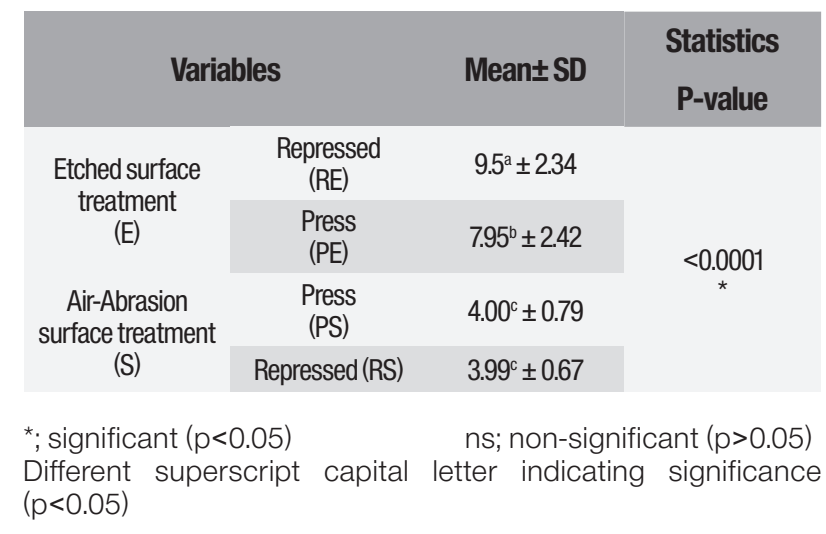



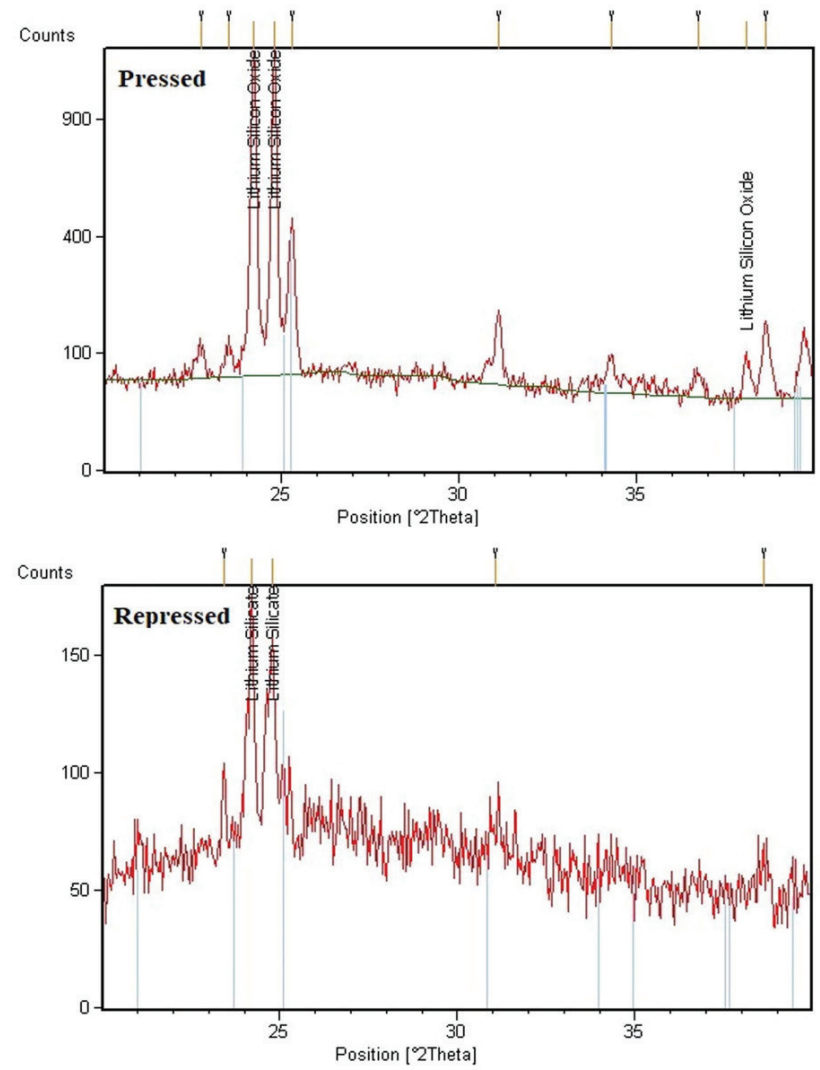

Figure 1 - X-ray diffraction (XRD) patterns of IPS e.max Press $(P)$ and $(R)$ showing peak positions in agreement with those of standard Lithium disilicate.
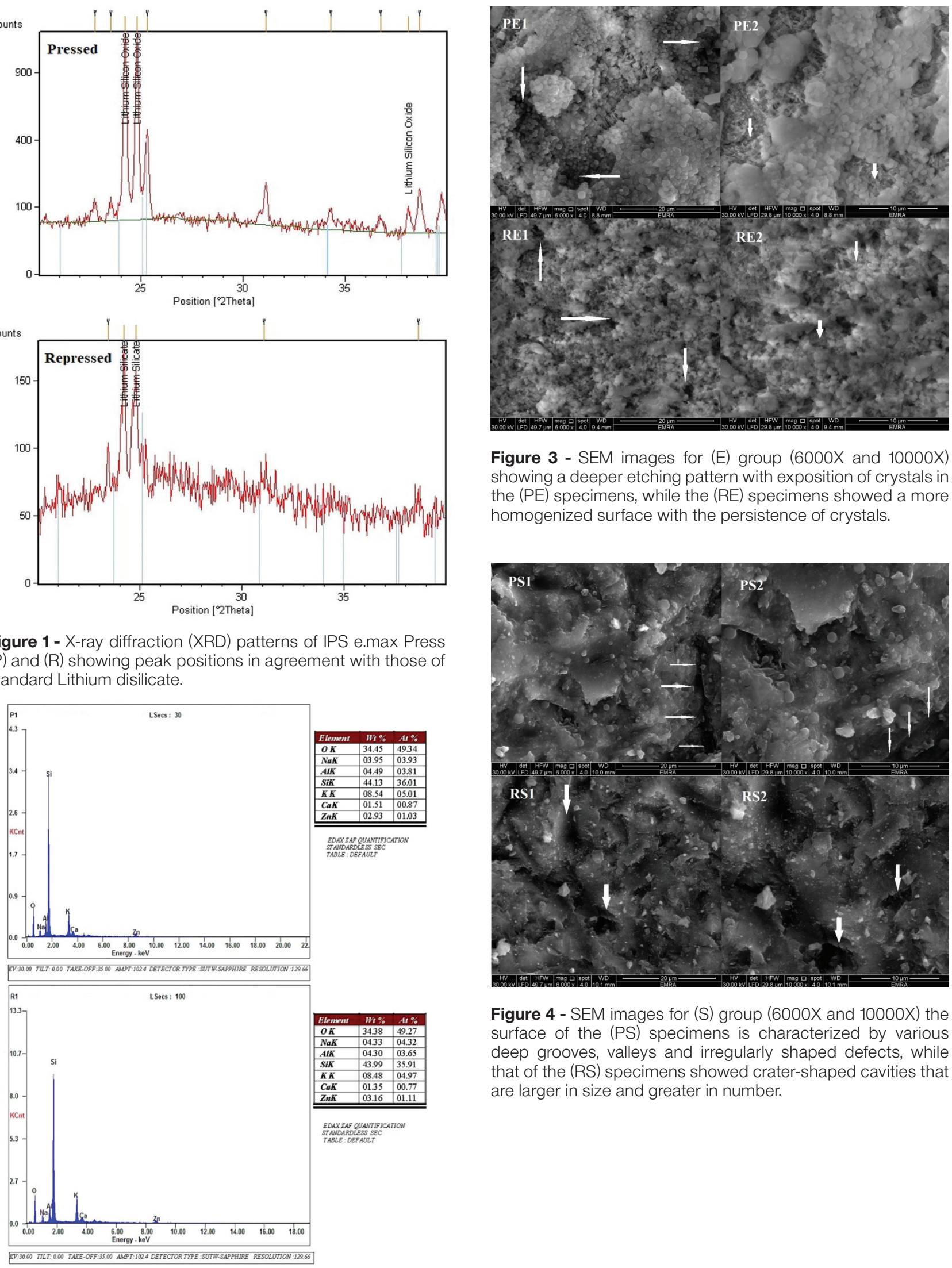

Figure 3 - SEM images for (E) group (6000X and 10000X) showing a deeper etching pattern with exposition of crystals in the (PE) specimens, while the (RE) specimens showed a more homogenized surface with the persistence of crystals.

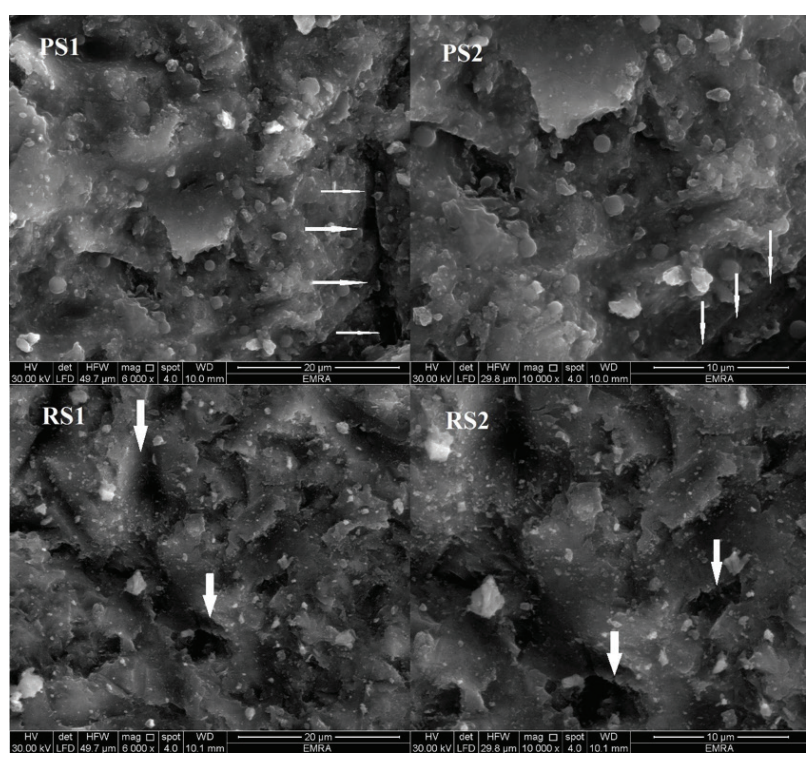

Figure 4 - SEM images for (S) group (6000X and 10000X) the surface of the (PS) specimens is characterized by various deep grooves, valleys and irregularly shaped defects, while that of the (RS) specimens showed crater-shaped cavities that are larger in size and greater in number.

Figure 2 - Microanalysis by EDAX of IPS e.max Press (P) and (R) groups. 


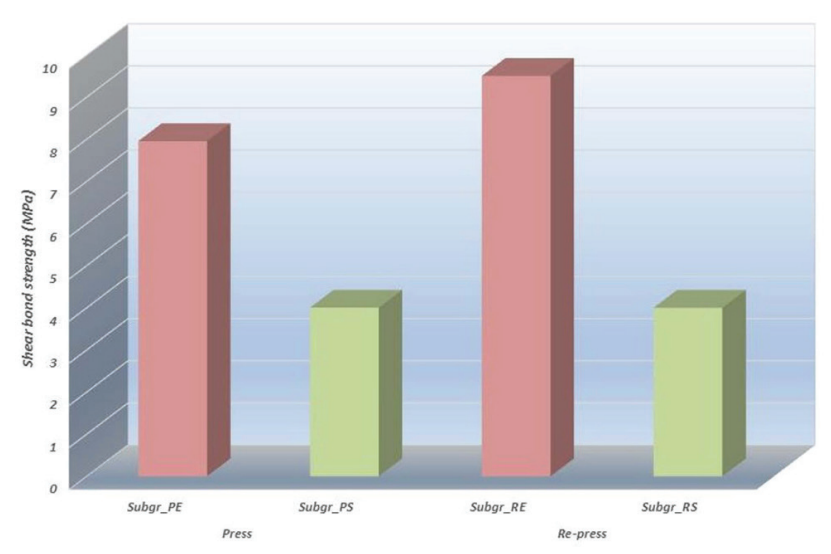

Figure 5 - Column chart of shear bond strength mean values for both groups with different surface treatment.

\section{Effect of Etching on the Bond Strength}

It was found that etching significantly increased the shear bond strength mean values of the tested specimens.

\section{Strength \\ Effect of Air-Abrasion on the Bond}

It was found that air-abrasion had no significant effect on the shear bond strength mean values of the tested specimens.

\section{Mode of Failure}

Frequent distribution of failure modes scores (\%) for both groups as a function of two surface treatments (Table II, Figure 6). The difference in the frequent distribution of failure modes scores between groups was statistically significant, as indicated by the chi-square test $(\mathrm{p}=<0.0001<0.05)$. The air-abrasion surface treatment showed a $100 \%$ Adhesive failure with both Pressed and Repressed specimens while the Acid Etching surface treatment showed a 100\% Mixed failure with Repressed specimens and a lower mixed failure $77.8 \%$ with the Pressed specimens.

Table II - Frequent distribution of failure modes scores (\%)

\begin{tabular}{|c|c|c|c|c|}
\hline \multirow{2}{*}{\multicolumn{2}{|c|}{ Variables }} & \multicolumn{3}{|c|}{ Failure modes } \\
\hline & & Adhesive & Cohesive & Mixed \\
\hline \multirow{2}{*}{$\begin{array}{l}\text { Pressed } \\
\text { (P) }\end{array}$} & Subgroup PE & 11.1 & 11.1 & 77.8 \\
\hline & Subgroup PS & 100 & 0 & 0 \\
\hline \multirow{2}{*}{$\begin{array}{l}\text { Repressed } \\
\text { (R) }\end{array}$} & Subgroup RE & 0 & 0 & 100 \\
\hline & Subgroup RS & 100 & 0 & 0 \\
\hline
\end{tabular}

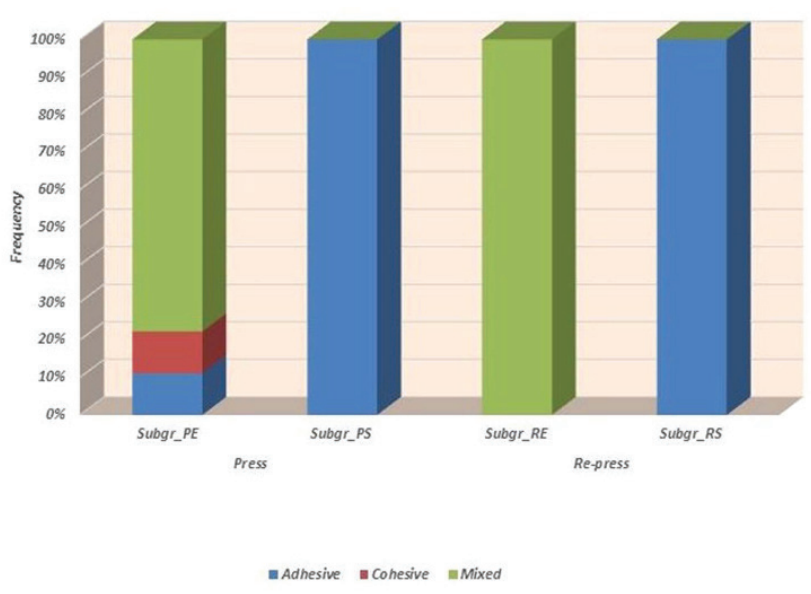

Figure 6 - Stacked column chart comparing the frequent distribution of failure modes scores for both groups with both adhesive approaches.

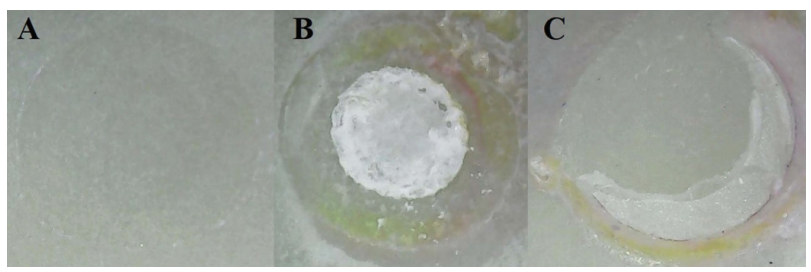

Figure 7 - Representative microscopic image showing (A) Adhesive, (B) Cohesive and (C) Mixed failure mode at 25x magnification.

\section{DISCUSSION}

The null hypothesis of the present study was rejected. A significant difference was found between the shear bond strength of acid-etched pressed and repressed groups. A significant difference was found between the shear bond strength of etched and air-abraded subgroups.

The bonding effectiveness of resin cement to an all-ceramic restoration has a significant impact on its strength. Thus, the cementation process plays a vital role in the clinical success of an all-ceramic restoration. It has been reported that some dental laboratories reuse the leftover material of previous heat pressing procedures to fabricate new restorations. [31,32] The effect of this procedure on the bond strength of resin cement to lithium disilicate glass-ceramics is unknown.

Bonded specimens were subjected to thermocycling in an attempt to stimulate the 
aging process occurring in the oral cavity. There is a considerable variation in the number of thermal cycles and the temperature extremes between studies. In the present study, the number of cycles used was 5000 cycles simulating thermal change for approximately 6 months in the oral cavity. The low-temperature point was $5{ }^{\circ} \mathrm{C}$, and the high-temperature point was $55^{\circ} \mathrm{C}$. $[34,35]$

Although many studies reported that there was a decrease in shear bond strength when the heat-pressed glass-ceramic surface was air-abraded with alumina oxide particles when compared with a heat pressed glassceramic surface etched with hydrofluoric acid. [26-30] Yet, air-abrasion was used in this study as its effect on repressed lithium disilicate glass-ceramics was unknown, and whether air-abrasion will affect the shear bond strength of the repressed ceramics was still to be investigated. Air-abrasion protocol used was the recommended by the manufacturer for conventional cementation of lithium disilicate glass-ceramics. Specimens with alumina oxide air-abrasion demonstrated the significantly lowest mean bond strength compared to those etched with hydrofluoric acid. This may be attributed to the inability of the air-abrasion to provide a mechanically retentive surface that is as efficient as etching with hydrofluoric acid.

Results of the present study showed that etching surface treatment recorded statistically higher shear bond strength than air-abrasion surface treatment with both tested groups (pressed and repressed). This goes in agreement with Guarda et al. [20], whose results showed that the etching procedure with hydrofluoric acid resulted in the highest bond strength with a statistically significant difference when compared with air-abrasion using alumina oxide particles.

The bond strength difference can be explained based on morphology created on both specimens, as confirmed by SEM pictures. Hydrofluoric acid etching caused the dissolution of the specimens glassy matrix. This dissolution extended to the depth of a few microns that were enough to enable the protrusion of the lithium disilicate crystals from the glass matrix. Elongated crystals and shallow irregularities were observed. The change in the surface morphology of the specimens treated with hydrofluoric acid increased the surface area required for the penetration and retention of resin cement into the micro-retentions of the treated surface. [26-39] (RE) showed higher shear bond strength than (PE) specimens which highlights the effect of repressing and this result may be attributed to the more homogenized surface with the persistence of crystals in the (RE) than that of the (PE) specimens as seen in the SEM pictures.

Failure mode showed that all specimens treated with air-abrasion had a 100\% adhesive failure, which is concurrent with our results that showed that air-abraded samples had much lower shear bond strength when compared with acid-etched specimens. All specimens treated with acid etching showed mixed adhesive and cohesive failures, which elaborate much stronger shear bond strength. This may be attributed to surface topography of air-abraded specimens seen in SEM images. The surface of the (PS) specimens was characterized by various deep grooves, valleys and irregularly shaped defects, while that of the (RS) specimens showed cratershaped cavities that are larger in size and greater in number than that of PS specimens. These defects affect the wettability of the adhesive to the specimens surface and may entrap air that negatively affects the bond strength.

\section{Limitations of the study}

1- Discs samples were used to investigate the bond strength thus the effect of the significant increase in bond strength to repressed specimens on the final strength of lithium disilicate restorations is still unknown.

2- Only Shear bond strength was used and not microShear or microtensile test. 


\section{CONCLUSION}

1- Repressing the leftover buttons for the construction of new lithium disilicate glassceramic restorations has no adverse effect on the bond strength of the resin cement to the ceramic.

2- Hydrofluoric acid surface treatment improves the shear bond strength and durability of resin cement bond to both pressed and repressed lithium disilicate glass-ceramic.

3- Air-abrasion cannot be considered as a reliable surface treatment when bonding to lithium disilicate glass-ceramics.

\section{Acknowledgments}

There is no Acknowledgments. ALL colleges who shared in this research were mentioned as authors.

\section{Funding}

This study was fully supported and funded and funded by the authors.

\section{Conflict of interest}

The authors have no proprietary, financial, or other personal interest of any nature or kind in any product, service, and/or company that is presented in this article.

\section{Regulatory Statement}

This study was exempted from the ethical committee as it is an invitro study.

\section{REFERENCES}

1. Albakry M, Guazzato M, Swain MV. Biaxial flexural strength, elastic moduli, and $x$-ray diffraction characterization of three pressable all-ceramic materials. JProsthetDent. 2003 Apr;89(4):374-80. doi:10.1067/mpr.2003.42.PMID: 12690350.

2. Belli R, GeinzerE, Muschweck A,Petschelt A, Lohbauer U. Mechanical fatigue degradation of ceramics versus resin composites for dental restorations. Dent Mater.2014 Apr;30(4):424-32. doi:10.1016/j.dental.2014.01.003. Epub 2014Feb 17. Erratum in:Dent Mater. 2014 0ct;30(10):1204. PMID:24553249.

3. Blatz MB, Sadan A, Kern M. Resin-ceramic bonding: a review of the literature. J ProsthetDent. 2003 Mar;89(3):268-74. doi: 10.1067/mpr.2003.50.PMID: 12644802.

4. Borges GA, Sophr AM, de Goes MF, Sobrinho LC, Chan DC. Effect of etching and airborne particle abrasion on the microstructure of different dental ceramics. JProsthet Dent. 2003 May;89(5):479-88. doi: 101016/s0022-3913(02)52704-9. PMID: 12806326.
5. Kalavacharla VK, Lawson NC, Ramp LC, Burgess JO. Influence of Etching Protocol and Silane Treatment with a Universal Adhesive on Lithium Disilicate Bond Strength. Oper Dent. 2015 Jul-Aug;40(4):372-8. doi: 10.2341/14-116-L. Epub2014 Dec 23.PMID:25535784.

6. Sundfeld Neto D, Naves LZ, Costa AR, Correr AB, Consani S, Borges GA, Correr-Sobrinho L. The Effect of Hydrofluoric Acid Concentration on the Bond Strength and Morphology of the Surface and Interface of Glass Ceramics to a Resin Cement. Oper Dent. 2015 Sep-0ct;40(5):470-9. do: 10.2341/14-133-L Epub 2015 Mar 12.PMID: 25764043.

7. Heintze SD, Albrecht T, Cavalleri A, Steiner M. A new method to test the fracture probability of all-ceramic crowns with a dual-axis chewing simulator. Dent Mater.2011Feb;27(2):e10-9. doi:10.1016/j.dental.2010.09.004. Epub 2010 Oct6.PMID:20932564.

8. Meereis CT, de Souza GB, Albino LG, Ogliari FA, PivaE, Lima GS. Digital Smile Design for Computer-assisted Esthetic Rehabilitation: Two-year Follow-up Oper Dent. 2016 Jan-Feb;41(1):E13-22. do: 10.2341/14-350-S. Epub 2015 Oct28. PMID:26509231.

9. Moretto G,Pupo YM, Bueno AL, Araujo FO. Prosthetic Rehabilitation of a Patient With Gastroesophageal Reflux Disease: Five-Year Follow-up. Oper Dent 2016 Mar-Apr;41(2):132-7.doi:10.2341/14-297-0. Epub 2015 0ct 8.PMID:26449592

10. Emslander A, Reise M, Eichberger M,Uhrenbacher J, Edelhoff D, Stawarczyk B. Impact of surface treatment of different reinforced glass-ceramic anterior crowns on load bearing capacity. Dent Mater J. 2015;34(5):595-604. doi: 10.4012/dmj.2014-294.PMID:26438982.

11. Pieger S, Salman A, Bidra AS. Clinical outcomes of lithium disilicate single crowns and partial fixed dental prostheses: a systematic review. J Prosthet Dent. 2014 Jul;112(1):22-30. doi: 10.1016/.jprosdent.2014.01.005. Epub 2014 Mar 24.PMID:24674802

12. GehrtM, WolfartS, Rafai N, Reich S, EdelhoffD. Clinical results of lithiumdisilicate crowns after up to 9 years of service. Clin Oral Investig. 2013 Jan;17(1):275-84. doi: 10.1007/s00784-012-0700-x. Epub 2012 Mar 7.PMID: 22392163.

13. Wolfart S, Eschbach S, Scherrer S, Kern M. Clinical outcome of three-unit lithium-disilicate glass-ceramic fixed dental prostheses: up to 8 years results. Dent Mater.2009Sep;25(9):e63-71. doi:10.1016/.jdental.2009.05.003. Epub 2009 Jun 11.PMID: 19523678.

14. Powers JM, Farah FJ, O'Keefe KL, Kolb B, Udrys G. Guide to all-ceramic bonding Dental Advisor 2009;2:1-12.

15. Piwowarczyk A, Lauer HC, Sorensen JA. In vitro shear bond strength of cementing agents to fixed prosthodontic restorative materials. J Prosthet Dent. 2004 Sep;92(3):265-73. doi:10.1016/.jprosdent.2004.06.027.PMID: 15343162.

16. Peutzfeldt A, Sahafi A, Flury S. Bonding of restorative materials to dentin with various luting agents. Oper Dent. 2011May-Jun;36(3):266-73. doi: 10.2341/10236-L. Epub 2011 Jul 8.PMID:21740244.

17. Heintze SD, Cavalleri A,Zellweger G, Büchler A, Zappini G. Fracture frequency of all-ceramic crowns during dynamic loading in a chewing simulator using different loading and luting protocols. Dent Mater.2008 0ct;24(10):1352-61. doi: 10.1016/.j.dental.2008.02.019. Epub 2008 Apr 22.PMID: 18433859.

18. Soares CJ, Soares PV, Pereira JC, Fonseca RB. Surface treatment protocols in the cementation process of ceramic and laboratory-processed composite restorations: a literature review. JEsthet Restor Dent. 2005;17(4):224-35. doi: 10.1111/j.1708-8240.2005.tb00119.x. PMID: 16231493.

19. Colares RC, Neri JR, Souza AM, Pontes KM, Mendonça JS, Santiago SL. Effect of surface pretreatments on the microtensile bond strength of lithiumdisilicate ceramic repaired with composite resin. Braz Dent J. 2013;24(4):34952. doi: 101590/0103-6440201301960.PMID:24173254. 
20. Guarda GB, Correr AB, Goncalves LS, Costa AR, Borges GA, Sinhoreti MA, Correr-Sobrinho L. Effects of surface treatments, thermocycling, and cyclic loading on the bond strength of a resin cement bonded to a lithium disilicate glass ceramic. Oper Dent. 2013 Mar-Apr;38(2):208-17.doi:10.2341/11-076-L. Epub 2012 Aug 3.PMID:22856682.

21. Kursoglu P,Motro PF, Yurdaguven H. Shear bond strength of resin cement to an acid etched and a laser irradiated ceramic surface. J Adv Prosthodont 2013 May;5(2):98-103. doi:10.4047/jap.2013.5.2.98. Epub2013 May 30.PMID: 23755333; PMCID:PMC3675300

22. Nagai T,Kawamoto Y,Kakehashi Y,Matsumura H. Adhesive bonding of a lithium disilicate ceramic material with resin-based luting agents. J Oral Rehabil. 2005 Aug;32(8):598-605. doi: 10.1111/.1365-2842.2005.01464.x. PMID: 16011639 .

23. Panah $F G$, Rezai SM, Ahmadian L The influence of ceramic surface treatments on the micro-shear bond strength of composite resin to IPS Empress 2.J Prosthodont.2008 Jul;17(5):409-14. doi: 10.1111/.j1532-849X.2007.00296.x. PMID: 18717831.

24. Tian T, Tsoi JK, Matinlinna JP,Burrow MF. Aspects of bonding between resin luting cements and glass ceramic materials. Dent Mater.2014 Jul;30(7):e147-62. doi:10.1016/.jdental.2014.01.017. Epub 2014Mar 6.PMID: 24612840.

25. Pisani-Proenca J, Erhardt MC, Valandro LF, Gutierrez-Aceves G, BolanosCarmona MV, Del Castillo-Salmeron R, Bottino MA. Influence of ceramic surface conditioning and resin cements on microtensile bond strength to a glass ceramic. J Prosthet Dent. 2006 Dec;96(6):412-7.doi: 10.1016/j. prosdent.2006.09.023.PMID:17174658.

26. Ayad MF,Fahmy NZ, Rosenstiel SF.Effect of surface treatment on roughness and bond strength of a heat-pressed ceramic. JProsthet Dent. 2008 Feb;99(2):123-30. doi:10.1016/S0022-3913(08)60028-1.PMID: 18262013.

27. Ozcan M, Vallittu PK. Effect of surface conditioning methods on the bond strength of luting cement to ceramics. Dent Mater.2003 Dec;19(8):725-31. doi: 10.1016/s0109-5641(03)00019-8.PMID: 14511730

28. Salvio LA, Correr-Sobrinho L, Consani S, Sinhoreti MA, de Goes MF, Knowles JC. Effect of water storage and surface treatments on the tensile bond strength of IPSEmpress 2 ceramic. JProsthodont. 2007 May-Jun;16(3):192-9. doi: 10.1111/.1532-849X.2006.00171.X.PMID:17581181.
29. Spohr AM, Sobrinho LC, Consani S, Sinhoreti MA, Knowles JC. Influence of surface conditions and silane agent on the bond of resin to IPSEmpress2 ceramic. Int JProsthodont. 2003 May-Jun;16(3):277-82. PMIID: 12854792

30. Attia A. Influence of surface treatment and cyclic loading on the durability of repaired all-ceramic crowns. J Appl Oral Sci. 2010 Mar-Apr;18(2):194-200. doi: 101590/s1678-77572010000200015. PMID:20485932; PMCID:PMC5349757.

31. Albakry M, Guazzato M, Swain MV. Biaxial flexural strength and microstructure changes of two recycled pressable glass ceramics. J Prosthodont. 2004 Sep;13(3):141-9. doi: 10.1111/11532-849X.2004.04025.x. PMID: 15345013.

32. Gorman CM, Horgan K, Dollard RP,Stanton KT.Effects of repeated processing on the strength and microstructure of a heat-pressed dental ceramic.J ProsthetDent. 2014 Dec;112(6):1370-6. doi: 10.1016/jprosdent2014.06.015. Epub 2014 Sep 23.PMID:25258270.

33. Chung KH, Liao JH, Duh JG, Chan DC. The effects of repeated heat-pressing on properties of pressable glass-ceramics. J Oral Rehabil. 2009 Feb;36(2):132-41. do: 10.1111/.1365-2842.2008.01909.x. Epub 2008 Aug 4.PMID: 18681936.

34. Garboza CS, Berger SB, Guiraldo RD, Fugolin AP, Gonini-Júnior A, Moura SK, Lopes MB. Influence of Surface Treatments and Adhesive Systems on Lithium Disilicate Microshear Bond Strength. Braz Dent J. 2016 Jul-Aug;27(4):458-62. doi: 101590/0103-6440201600624.PMID:27652711.

35. Shimada Y, Yamaguchi S, Tagami J. Micro-shear bond strength of dual-cured resin cement to glass ceramics. Dent Mater. 2002 Jul;18(5):380-8. doi:10.1016/ S0109-5641(01)00054-9.PMID: 12175577.

36. Morresi AL,D'Amario M, Capogreco M, Gatto R, Marzo G, D'Arcangelo C, Monaco A. Thermal cycling for restorative materials: does a standardized protocol exist in laboratory testing? A literature review. J Mech Behav Biomed Mater.2014 Jan;29:295-308. doi:10.1016/j.jmbbm.2013.09.013. Epub 2013 Sep 27.PMID: 24135128.

37. Gale MS, Darvell BW. Thermal cycling procedures for laboratory testing of dental restorations. J Dent. 1999 Feb;27(2):89-99. doi: 10.1016/s03005712(98)00037-2.PMID: 10071465.

\section{Amr EL-Etreby \\ (Corresponding address)}

Associate Professor of Fixed Prosthodontics

Faculty of Dentistry, Ain Shams University, Cairo, Egypt.

43, Ahmed Oraby St, Mohandeseen 12411, Giza, Egypt.

Email: prof.amreletreby@gmail.com

Date submitted: 2020 Aug 23

Accept submission: 2020 Nov 04 